\title{
Negative Mental Health factors in Children orphaned by AIDS: Natural mentoring as a palliative care
}

\author{
Francis N. Onuoha1* ${ }^{*}$, Tsunetsugu Munakata1 \\ Philip A.E. Serumaga-Zake² \\ Rebecca M. Nyonyintono ${ }^{3}$, and Stephen M. Bogere 4

\begin{abstract}
1 University of Tsukuba, Graduate School of Comprehensive Human Sciences, Tsukuba, Japan
2 North-West University, School of Economics \& Decision Sciences, Mafikeng, South Africa

${ }^{3}$ School of Postgraduate Studies, Ndejje University, Kampala, Uganda
\end{abstract} \\ ${ }^{4}$ Makerere University, Department of Sociology, Kampala, Uganda
}

\begin{abstract}
The study examined the psychosocial mental health of some children whose parents died of AIDS (n=373) in Uganda and South Africa. The design has 2 control groups: other-causes orphaned $(n=287)$, and non-orphaned $(n=290)$ children (grand mean age $=13.59, S D=2.34)$. We utilized a battery of standardized psychosocial measures to estimate mental health in the groups. Natural mentoring relationship was estimated with the Ragins and McFarlin (1990) Mentor Role Instrument. Results indicated that AIDS-orphaned children showed highest negative, and lowest positive mental health factors in the 3 groups. Children in a mentoring relationship showed better mental health factors than those without a mentor. AIDS-orphaned children showed significant negative mental health factors than did children in the control groups. We ascribed their highest negative mental health condition to the incidence of higher double parental loss in the AIDS-orphaned children, and suggested natural mentorship care as a palliative care against negative mental health.
\end{abstract}

Keywords: mental health, AIDS-orphaned children, non-orphaned children, natural mentoring 


\section{Introduction}

Studies of childhood parental loss suggest that orphans tend to experience social depression

(Furukawa, Yokouchi, Hirai, Kitamura, \& Takahashi, 1999), personality disorders (Paris, Zweig-Frank, \& Guzder, 1994) and anxiety/insomnia (Tweed, Schoenbach, George, \& Blazer, 1989). Parents are arguably the most fundamental agent of social stabilization in the lives of children. They have the inalienable primary responsibility to provide for the material, intellectual, psychosocial support needs of their offspring (Maxwell, 1998). As role models, counselors, and educators, parents make significant impacts on the belief systems, hopes, and aspirations of their infants. However, as children make the inevitable transition to adolescence they come into contact with a broad array of non-parent adults who may exert strong influences on the children (Beam, Chen, \& Greenberger, 2002).

Childhood parental acculturization tends to persist into early adulthood (Flaherty \& Richman, 1986). Children who are groomed into reciprocation as a way of life may internalize and apply the social skill in later life to build own social support network. But children without parents may miss out in this important social networking skill training. Support from parents during childhood may have enduring physical and psychosocial health benefits (Scroufe, Carlson, Levy, \& Egeland, 1999). Parental support, tangible (monetary, social participation, material care) or intangible (emotional care, cognitive guidance), is desirable to fulfill the affective and economic functions of the family (Turnbull \& Turnbull, 2001). Yet the direct consequence of orphanhood is the reduced availability of parental support (UNICEF, 2004).

Orphan children seem socially deprived. They tend to encounter higher emotional distress, 
hopelessness, and frustration (Mbozi, Debit, \& Munyati, 2006) than non-orphans. Most orphans may be distressed by their new circumstance that may require them to cater for themselves and/or assume care-giving responsibility for their younger ones. Sexual abuse (Pridmore \& Yates, 2005) and social discrimination (Cluver, Gardner, \& Operario, 2008; Nyblade, Pande, Mathur, MacQuarrie, Kidd, \& Banteyerga, 2003) against orphans have been reported. Abebe and Aase (2007), however, disagree with the symptomatic perceptions of orphans. They argue that the symptomatic constructs of orphans are media-induced stereotyping, orchestrated by academic scholars of the traditionalist persuasion. Most orphans have the resilience and agency (Abebe \& Aase, 2007) to get on with the challenges of life following parental death.

Chitiyo, Changara, and Chitiyo (2007) suggest that AIDS-orphaned children may be unique orphans. Unlike other children orphans, they may begin to grieve long before parental death(s), owing to the protracted human "wasting" AIDS-defining illnesses that may precede death. According to UNAIDS, UNICEF, and USAID (2004, p.11), "an especially important and distinctive characteristic of HIVIAIDS in regards to orphaning is that AIDS is more likely than other causes of death to create double orphans." In the sub-Sahara African countries of South Africa and Uganda, double orphanhood (or the loss of both parents) is four times more likely in AIDS-affected homes (UNAIDS, UNICEF, \& USAID, 2004) than in other households, where civil war, vehicular accident (Cluver, Gardner, \& Operario, \& 2008), feminine and disease (Abebe \& Aase, 2007) may account for double parental loss.

Subbarao, Mattimore, and Plangemann (2001) identified 7 care options for orphan children in most 
African countries. Atop these options is fostering, adjudged to be attuned to the support culture of the African extended family system. Foster children, however, tend to experience discrimination in food allocation, domestic exploitation and abuse (Deininger, Garcia, \& Subbarao, 2003) that may negatively impact on their psychological health. Furthermore, the magnitude of the AIDS-orphan crisis in sub-Saharan Africa, seems to so overstretch the fostering capacity of most families that the collapse of fostering seems imminent (UNICEF, 2003), fueling the need for a complementary/alternative care model. In a national US representative survey of adults, spontaneous ties with children accounted for two-thirds of the reported adult-child relationships (MENTOR, 2002). The children experienced guidance, counseling, role model, and ego ideal functions (Barrera \& Prelow, 2000) from the adult mentors. Nonparent adults or natural mentors may be an overlooked resource for the positive psychological adjustment of vulnerable children (Rhodes et al., 1992).

The purpose of the present study is to examine the psychosocial mental health of children orphaned by AIDS, and to estimate the effect of natural mentoring relationship on mental health in the children. Natural (informal) mentoring is different from organizational (formal) mentorship (Sipe, 2002). The latter (formal mentoring) is given at the workplace by senior personnel to junior colleagues; the former is provided outside the workplace, in homes and communities (DuBois \& Silverthorn, 2005) by nonparent support figures (Rhodes, Ebert, \& Fischer, 1992) - such as local school teachers, neighbors, elders and religious leaders, grandmothers/fathers, and other significant family/nonfamily adult members. 


\section{Method}

\section{Procedure}

We applied and received approval for the study protocol from the Uganda National Council for Science and Technology (UNCST). The School of Economics \& Decision Sciences, North-West University, Mafikeng, South Africa assented to the study protocol. So did the Department of Human Care Science, Graduate School of Human Sciences, University of Tsukuba, Japan, the host institution for the study. The study participants were recruited at community schools, and NGO child support centers at Mafikeng (North-West Province, South Africa) and Kampala (Kampala District, Uganda). Higher generalizability of the study outcome informed our choice of the international sample. The UN definition of orphanhood as the loss of one or both parents (UNAIDS, UNICEF, \& USAID, 2004) was adopted. We also utilized the UN definition of a child as persons aged 0-17 years, following which 88 children were dropped from the prospective sample $(\mathrm{N}=1,040)$ in the data analysis. We explained the study objectives to the community school and child support center heads/staff, who sought the voluntary participation of the children. To the children, the fact that the study was about orphans was not disclosed in order to check response

biases. Interviewers were Luganda (Uganda) and Xhosa/Afrikaan (South Africa) speaking research collaborators. When expedient the interviewer-administered questionnaire method was adopted, particularly for the tender-aged or low education children; otherwise the self-report method was dominantly used. The interview duration lasted approximately 45 minutes per session.

\section{Participants}


Nine hundred and fifty-two (952) children of Ugandan $(n=459)$ and South African $(n=492)$ origins validly participated in the study. The design has 3 groups: AIDS-orphaned, other-causes orphaned, and non-orphaned children. To determine orphan status, we asked each participant: "Is your father living? (Yes/No); is your mother living? (Yes/No)." Children who checked "No", were asked: "If father or/and mother not living, what was the cause of death?" Response choices were: "1. HIVIAIDS, 2. War, 3.

Others, 4. Don't know." Children who checked HIVIAIDS were assigned to the AIDS-orphaned group $(n=373)$.

Owing to the shame associated to HIV infection, children may feign ignorance of HIV-related cause of parental death (Chitiyo et al., 2007; Gillespie, Norman, \& Finley, 2005). We assigned to the AIDS-orphaned group, children when answered "Don't Know" to the cause of parental death, if their both parents were deceased. The criterion is in consonance with the UN defined essential characteristic of AIDS-induced orphanhood. A negligible few children were also assigned to this group utilizing the "verbal autopsy" (Hosegood, Vanneste, \& Timaeus, 2004) accounts of the community school and child support center heads, as explained elsewhere. Children who checked "War/Others" as the cause of father or/and mother death were assigned to the orphaned by other causes group ( $n=289)$, and children whose father and mother were living were assigned to the non-orphaned group ( $n=290)$.

\section{Measures}

To assess anxiety, we used the Anxiety Subscale of the renowned General Health Questionnaire (GHQ-28, Golderberg \& Hillier, 1979). The 6-item subscale (alpha $=.81)$ negatively $(r=-.34, p<.01)$ 
correlated with Rosenberg's Self Esteem, and positively $(r=.40, p<.01)$ with the Weissman, Orvaschel, and Padian (1980) CES-DC (Center for Epidemiological Studies Depression Scale for Children) as adapted.

We assessed depression with the Weissman et al. (1980) CES-DC, which test-retest reliability and concurrent validity are adequate (Faulstich, Carey, Ruggiero, Enyart, \& Gresham, 1986). We utilized the first 10 items (somatic complaints, 5 items; negative affects, 3 items; and positive affects, 2 items) of the 20-item CES-DC. To strengthen the internal stability of the measure (alpha= .77 ), we excluded the two positive affect items during analysis. Sample items on the 8-item CES-DC include: "I was bothered by things that usually don't bother me; I didn't feel like eating, I wasn't very hungry; I wasn't able to feel happy, even when friends tried to make me feel good; I felt like I was too tired to do things."

To estimate perceived social support, we adapted 6-items (alpha=.83) from the 15 -item Schwarzer and Schulz (2000) Received Support Scale. The measure positively associated with the Rosenberg's Self-esteem $(r=.36, p<.01)$ and negatively with anxiety $(r=-.38, p<.01)$. The measure requires the respondent to "think about person(s) that is closest to you - your friend(s), guardian(s) or parent(s)/foster parent(s) - how does this person treat you?" Sample items are: S/he "is there when I need him/her; shows love to me; takes care of my financial needs; in general, I am satisfied with the way s/he treats me."

We measured self-esteem with the Rosenberg (1965) Self-Esteem Scale (RSE), the most utilized measure of self-esteem (Blascovich \& Tomaka, 1991) that estimates favorable/unfavorable attitude 
toward the self. The Cronbach alpha for the Scale in the present study is .60, which compares with the value found by Lorenzo-Hernandez and Ouellette (1998). The measure showed admissible discriminant validity against anxiety $(r=-.34, p<.01)$, and social discrimination $(r=-.40, p<.01)$.

To estimate social discrimination, we utilized the modified 1995 Detroit Area Study Measure of Discrimination (alpha $=.78)$. Typical questions are: In your daily life, compared to other people around you, do you: Feel differently treated? Feel unfairly treated? Made to feel inferior? Prevented from doing things others are allowed to do? People behave as though they are afraid of you? The measure appreciably correlated positively with depression $(r=.38, p<.01)$, child abuse $(r=.30, p$ $<.01)$, but negatively with social support $(r=-.25, p<.01)$.

To assess child abuse, we asked 4 questions, each of which estimates the physical, verbal, sexual, and labor dimensions of child abuse (Bagley \& King, 1990): Are you - physically beaten in a manner you consider unfair; verbally abused in a manner you consider unfair; forced to "sleep"/have sex with anyone; forced against your wish to work on the farm for someone? The alpha reliability of the measure, which discriminated depression $(r=.21, p<.01)$ and perceived social support $(r=-.36, p$ $<.01)$ is .76 .

We assessed parental/foster care with the Parker, Tupling, and Brown (1979) Parental Bonding Instrument (PBI). The 25-item PBI assesses both parental care and parental over-protection. The "care" dimension estimates empathy, affection, warmth, and independence. "Over-protection" comprises parental intrusion, infantilism, and control. Support for the reliability and validity of the PBI as a measure of both actual and perceived parenting has been reported (Neale et al., 1994). We utilized 8 items in 
the "care" subscale (alpha $=.86)$ in the present study. Typical items include parents/foster parents: are affectionate to me; understand my problems and worries; let me do things I enjoy doing; enjoy discussing things with me; give me as much freedom as I want.

Negative mental health factors (24 items, alpha $=.87$ ) is the summation of child abuse, depression, social discrimination, and anxiety scores. Positive mental health factors ( 23 items, alpha $=.86)$ is the sum of parental/foster care, perceived social support, and self-esteem scores. Responses to all items on the study measures were scored from 0 (never) to 3 (always) in which high scores denoted high presence of the construct under examination.

In consonance with the operational definition of natural mentoring relationship (Rhodes et al., 1992; Zimmerman, Bingenheimer, \& Notaro, 2002), we asked the participants: Other than your parent(s) or foster parent(s) is there any adult person(s) in the neighborhood you go to for support and guidance for most things you do (Yes/No)? If "Yes," how often do you meet this person (0. Rarely, 1. Sometimes, 2. Often, 3. Very often)? Children who answered "Yes", and checked any of the 1-3 meeting frequencies were classified to be in a mentoring relationship. These children $(n=714)$ rated the Ragins' Mentor Role Instrument (MRI) that estimates parental, modeling, counseling, friendship, and support roles by the mentor to the mentee. The 33-item MRI (Ragins \& McFarlin, 1990) has 3 items per its 11 mentor roles measured on a 7-point likert scale of 1 (strongly disagree) to 7 (strongly agree). We excluded the 6 workplace-related formal mentor roles (ie, job sponsorship, coaching, protection, challenge, exposure and socialization), and utilized the 5 informal mentor roles (ie, parenting, counseling, modeling, acceptance, and friendship) each of which was estimated with 2 items 
on a 4-point likert response score of 0 (never) to 3 (always). The internal stability of the adapted MRI (alpha=.91) is comparable to the value found by Ragins and Cotton (1999). The instrument, which showed discriminant validity against anxiety $(r=-.16, p<.01)$ and social support $\quad(r=.38, p<.01)$, has the following sample items: Treats me as a son/daughter (parental role); represents who I want to be (modeling role); guides me to choose the career I want (counseling role); provides me support and encouragement (friendship); acts as a leader to me (acceptance). Expected mentoring score range is $0-30$, higher scores represent higher impact of the mentor's roles on the psychological health of the children.

\section{Analysis}

To estimate mental health in the AIDS-orphaned children, we performed the posthoc ANOVA of multiple mean comparison of mental health for the 3 control groups (Table 1). To test whether double orphans are more psychologically disadvantaged than single orphans (UNAIDS, UNICEF, \& USAID, 2004), we isolated the double-orphaned from the single-orphaned children and examined the effect of double-orphanhood on mental health in the two orphan statuses (AIDS-orphaned and other-causes orphaned children, Table 2). To estimate the effect of natural mentoring relationship on the mental health of the children, we undertook two analyses. First, we segregated into two all children (orphans and non-orphans) who reportedly are in mentoring relationship $(n=714)$ from those not in such relationship $(n=234)$ and examined mental health outcomes between them. Next, we separated into three children having a mentor from those not-having and performed the ANOVA between them for each of the 3 
Table 1

ANOVA showing mental health differences in the 3 groups

\begin{tabular}{|c|c|c|c|c|c|c|c|c|c|c|}
\hline \multirow[b]{2}{*}{ Variables } & \multicolumn{3}{|c|}{$\begin{array}{c}\text { Children orphaned } \\
\text { by AIDS } \\
\end{array}$} & \multicolumn{3}{|c|}{$\begin{array}{l}\text { Children orphaned } \\
\text { by other causes }{ }^{b} \\
\end{array}$} & \multicolumn{3}{|c|}{$\begin{array}{c}\text { Non-orphaned } \\
\text { children }^{c}\end{array}$} & \multirow[b]{2}{*}{ Posthoc } \\
\hline & $\mathrm{n}$ & $\mathrm{M}$ & SD & $\mathrm{n}$ & $\mathrm{M}$ & SD & $\mathrm{n}$ & $\mathrm{M}$ & SD & \\
\hline 1. Child abuse & 371 & 2.86 & 2.78 & 283 & 2.71 & 2.91 & 290 & 2.02 & 2.50 & $a>b^{d}, a>c^{*}$ \\
\hline 2. Depression & 373 & 10.49 & 4.91 & 285 & 9.69 & 4.95 & 289 & 9.20 & 5.14 & $a>b^{d}, a>c^{*}$ \\
\hline 3. Social discrimination & 371 & 6.18 & 3.95 & 284 & 5.24 & 3.81 & 290 & 5.92 & 4.38 & $a>b^{*}, a>c^{d}$ \\
\hline 4. Anxiety & 371 & 7.76 & 4.78 & 283 & 6.15 & 4.14 & 289 & 5.47 & 3.75 & $a>b^{*}, a>c^{*}$ \\
\hline 5. Parental/foster care & 371 & 11.31 & 5.11 & 284 & 12.6 & 5.97 & 290 & 13.67 & 5.84 & $a<b^{*}, a<c^{*}$ \\
\hline 6. Self-esteem & 373 & 15.30 & 4.83 & 285 & 16.3 & 4.72 & 290 & 17.27 & 4.61 & $a<b^{*}, a<c^{*}$ \\
\hline 7. Social support & 371 & 8.12 & 4.41 & 282 & 9.52 & 4.12 & 289 & 10.01 & 4.11 & $a<b^{*}, a<c^{*}$ \\
\hline 8. Negative mental health factors & 373 & 28.71 & 11.80 & 285 & 25.2 & 11.8 & 290 & 23.96 & 11.18 & $a>b^{*}, a>c^{*}$ \\
\hline 9. Positive mental health factors & 373 & 34.51 & 12.30 & 285 & 38.1 & 11.6 & 290 & 40.78 & 11.01 & $a<b^{*}, a<c^{*}$ \\
\hline
\end{tabular}

${ }^{\mathrm{d}}$ not significant, ${ }^{*} p<.05$ 
Table 2

ANOVA of mental health between AIDS-orphaned and other-causes orphaned children who are double-orphaned or single-orphaned

\begin{tabular}{|c|c|c|c|c|c|c|c|c|c|}
\hline \multirow[b]{2}{*}{ Variables } & \multirow[b]{2}{*}{ group } & \multirow[b]{2}{*}{$\mathrm{n}$} & \multicolumn{3}{|c|}{$\begin{array}{c}\text { Double-orphaned } \\
\text { children } \\
\end{array}$} & \multirow[b]{2}{*}{$\mathrm{n}$} & \multicolumn{3}{|c|}{$\begin{array}{c}\text { Single-orphaned } \\
\text { children } \\
\end{array}$} \\
\hline & & & $\mathrm{M}$ & SD & $\mathrm{F}$ & & $\mathrm{M}$ & SD & $\mathrm{F}$ \\
\hline \multirow[t]{2}{*}{ 1. Child abuse } & 1 & 267 & 2.91 & 2.84 & & 102 & 2.75 & 2.62 & \\
\hline & 2 & 52 & 2.94 & 2.88 & $0.01^{d}$ & 229 & 2.68 & 2.93 & $0.54^{d}$ \\
\hline \multirow[t]{2}{*}{ 2. Depression } & 1 & 268 & 10.22 & 5.03 & & 103 & 11.15 & 4.56 & \\
\hline & 2 & 53 & 9.53 & 5.15 & $0.82^{d}$ & 230 & 9.75 & 4.93 & $5.99^{* *}$ \\
\hline \multirow[t]{2}{*}{ 3. Social discrimination } & 1 & 267 & 6.03 & 3.97 & & 102 & 6.61 & 3.91 & \\
\hline & 2 & 52 & 5.92 & 3.43 & $0.03^{d}$ & 230 & 5.11 & 3.89 & $10.40^{\star *}$ \\
\hline \multirow[t]{2}{*}{ 4. Anxiety } & 1 & 267 & 7.64 & 4.81 & & 102 & 8.05 & 4.74 & \\
\hline & 2 & 52 & 6.56 & 4.04 & $2.33^{d}$ & 229 & 6.07 & 4.18 & $14.50^{* *}$ \\
\hline \multirow[t]{2}{*}{ 5. Parental/foster care } & 1 & 267 & 11.35 & 6.24 & & 102 & 11.24 & 5.85 & \\
\hline & 2 & 52 & 11.96 & 6.27 & $0.42^{d}$ & 230 & 12.71 & 5.93 & $4.40^{*}$ \\
\hline \multirow[t]{2}{*}{ 6. Self-esteem } & 1 & 268 & 15.40 & 4.73 & & 103 & 15.10 & 5.13 & \\
\hline & 2 & 53 & 14.13 & 3.92 & $3.37^{d}$ & 230 & 16.77 & 4.76 & $8.36^{\star *}$ \\
\hline \multirow[t]{2}{*}{ 7. Social support } & 1 & 267 & 8.19 & 4.47 & & 102 & 7.94 & 4.29 & \\
\hline & 2 & 52 & 8.29 & 4.22 & $0.02^{d}$ & 228 & 9.81 & 4.06 & $14.43^{\star *}$ \\
\hline \multirow[t]{2}{*}{ 8. Negative mental health factor: } & 1 & 268 & 28.18 & 11.88 & & 103 & 30.05 & 11.62 & \\
\hline & 2 & 53 & 26.13 & 11.74 & $1.32^{d}$ & 230 & 25.00 & 11.89 & $12.97^{\star *}$ \\
\hline \multirow[t]{2}{*}{ 9. Positive mental health factors } & 1 & 268 & 34.78 & 12.45 & & 103 & 33.94 & 12.15 & \\
\hline & 2 & 53 & 34.26 & 11.54 & $0.08^{d}$ & 230 & 38.98 & 12.45 & $13.20^{* *}$ \\
\hline
\end{tabular}


Table 3

t-test showing mental health differences between children having and children not-having a mentor in the 3 groups

\begin{tabular}{|c|c|c|c|c|c|c|c|c|c|c|}
\hline \multirow[b]{2}{*}{ Variables } & \multirow[b]{2}{*}{ G } & \multicolumn{3}{|c|}{$\begin{array}{c}\text { Children orphaned } \\
\text { by AIDS }\end{array}$} & \multicolumn{3}{|c|}{$\begin{array}{c}\text { Children orphaned } \\
\text { by other causes }\end{array}$} & \multicolumn{2}{|c|}{$\begin{array}{c}\begin{array}{c}\text { Non-orphaned } \\
\text { children }\end{array} \\
\end{array}$} & \multirow[b]{2}{*}{$t$} \\
\hline & & $\mathrm{n}$ & $M(S D)$ & $\mathrm{t}$ & $n$ & $M(S D)$ & $\mathrm{t}$ & $\mathrm{n}$ & $\mathrm{M}(\mathrm{SD})$ & \\
\hline \multirow{2}{*}{ 1. Child abuse } & $\mathrm{H}$ & 289 & $2.69(2.68)$ & & 207 & $2.45(2.75)$ & & 210 & $1.81(2.43)$ & \\
\hline & $\mathrm{NH}$ & 81 & $3.49(3.04)$ & $2.15^{*}$ & 75 & $3.45(3.22)$ & $2.40^{*}$ & 78 & $2.51(2.60)$ & $2.06^{*}$ \\
\hline \multirow[t]{2}{*}{ 2. Depression } & $H$ & 291 & $10.30(4.73)$ & & 209 & $9.58(4.87)$ & & 209 & $9.26(5.31)$ & \\
\hline & $\mathrm{NH}$ & 81 & $11.10(5.48)$ & $1.3^{\mathrm{d}}$ & 75 & $10.09(5.14)$ & $0.77^{\mathrm{d}}$ & 78 & $8.96(4.73)$ & $0.43^{\mathrm{d}}$ \\
\hline \multirow[t]{2}{*}{ 3. Social discrimination } & $H$ & 289 & $5.92(3.64)$ & & 208 & $5.13(3.85)$ & & 210 & $5.88(4.55)$ & \\
\hline & $\mathrm{NH}$ & 81 & $7.10(4.83)$ & $2.05^{*}$ & 75 & $5.63(3.70)$ & $0.97^{\mathrm{d}}$ & 78 & $5.91(3.87)$ & $0.06^{\mathrm{d}}$ \\
\hline \multirow[t]{2}{*}{ 4. Anxiety } & $H$ & 289 & $7.33(4.51)$ & & 207 & $6.09(4.06)$ & & 209 & $5.37(3.61)$ & \\
\hline & $\mathrm{NH}$ & 81 & $9.28(5.41)$ & $2.98^{\star *}$ & 75 & $6.36(4.38)$ & $0.48^{d}$ & 78 & $5.67(4.14)$ & $0.60^{d}$ \\
\hline \multirow[t]{2}{*}{ 5. Parental/foster care } & $\mathrm{H}$ & 289 & $11.92(6.08)$ & & 208 & $12.72(5.66)$ & & 210 & $14.43(5.43)$ & \\
\hline & $\mathrm{NH}$ & 81 & $9.01(5.66)$ & $3.86^{* \star}$ & 75 & $12.04(6.75)$ & $0.78^{d}$ & 78 & $11.60(6.50)$ & $3.43^{* \star}$ \\
\hline \multirow[t]{2}{*}{ 6. Self-esteem } & $\mathrm{H}$ & 291 & $15.68(4.71)$ & & 209 & $16.39(4.65)$ & & 210 & $17.68(4.57)$ & \\
\hline & $\mathrm{NH}$ & 81 & $13.98(5.06)$ & $2.84^{* *}$ & 75 & $15.81(4.81)$ & $0.91^{d}$ & 78 & $16.24(4.60)$ & $2.36^{*}$ \\
\hline \multirow[t]{2}{*}{ 7. Social support } & $\mathrm{H}$ & 289 & $8.56(4.39)$ & & 206 & $9.93(3.94)$ & & 209 & $10.56(3.75)$ & \\
\hline & $\mathrm{NH}$ & 81 & $6.56(4.16)$ & $3.67^{\star \star}$ & 75 & $8.36(4.44)$ & $2.70^{*}$ & 78 & $8.67(4.66)$ & $3.23^{*}$ \\
\hline \multirow[t]{2}{*}{ 8. Negative mental health factors } & $\mathrm{H}$ & 291 & $27.58(10.90)$ & & 209 & $24.57(11.57)$ & & 210 & $23.63(10.91)$ & \\
\hline & $\mathrm{NH}$ & 81 & $32.64(14.04)$ & $3.00^{* *}$ & 75 & $27.08(12.29)$ & $1.59^{d}$ & 78 & $24.49(11.84)$ & $0.58^{\mathrm{d}}$ \\
\hline \multirow[t]{2}{*}{ 9. Positive mental health factors } & $\mathrm{H}$ & 291 & $35.88(12.32)$ & & 209 & $38.76(11.23)$ & & 210 & $42.47(10.08)$ & \\
\hline & $\mathrm{NH}$ & 81 & $29.53(11.16)$ & $4.19^{* *}$ & 75 & $35.92(12.13)$ & $1.84^{\mathrm{d}}$ & 78 & $36.49(12.27)$ & $3.85^{* *}$ \\
\hline
\end{tabular}

\footnotetext{
${ }^{d}$ not significant ${ }^{*} p<.05{ }^{* *} p<.01 \quad G=$ Group: $H=$ reported having a mentor, $\quad \mathrm{NH}=$ reported not-having a mentor
} 
Table 4

ANOVA of ranked mentoring relationship on mental health in the 3 groups

\begin{tabular}{|c|c|c|c|c|c|c|c|c|c|c|}
\hline \multirow[b]{2}{*}{ Variables } & \multirow[b]{2}{*}{ MR } & \multicolumn{3}{|c|}{$\begin{array}{c}\text { Children orphaned } \\
\text { by AIDS }\end{array}$} & \multicolumn{3}{|c|}{$\begin{array}{c}\text { Children orphaned } \\
\text { by other causes }\end{array}$} & \multicolumn{3}{|c|}{$\begin{array}{c}\text { Non-orphaned } \\
\text { children }\end{array}$} \\
\hline & & $\mathrm{n}$ & $M(S D)$ & Posthoc & $\mathrm{n}$ & $M(S D)$ & Posthoc & $\mathrm{n}$ & $M(S D)$ & Posthoc \\
\hline \multirow[t]{3}{*}{ 1. Negative mental health factors } & 1 & 113 & $32.73(13.40)$ & & 98 & $26.40(12.58)$ & & 13 & $21.31(8.77)$ & \\
\hline & 2 & 102 & $28.51(10.20)$ & & 69 & $25.90(11.66)$ & & 54 & $23.13(8.58)$ & \\
\hline & 3 & 158 & $25.96(10.80)$ & $a>b^{*}, a>c^{*}, b>c^{*}$ & 118 & 23.70(11.21) & $a>b^{d}, a>c^{d}, b>c^{d}$ & 141 & $24.23(11.80)$ & $a<b^{d}, a<c^{d}, b<c^{d}$ \\
\hline \multirow[t]{3}{*}{ 2. Positive mental health factors } & 1 & 113 & $32.73(13.40)$ & & 98 & $26.40(12.58)$ & & 13 & $21.31(8.77)$ & \\
\hline & 2 & 102 & $33.16(11.50)$ & & 69 & $35.80(10.17)$ & & 54 & $37.31(10.30)$ & \\
\hline & 3 & 158 & $39.77(11.70)$ & $a<b^{*}, a<c^{*}, b<c^{*}$ & 118 & $42.10(10.26)$ & $a<b^{d}, a<c^{d}, b<c^{*}$ & 141 & $44.78(8.83)$ & $a>b^{d}, a<c^{d}, b<c^{*}$ \\
\hline
\end{tabular}

${ }^{d}$ not significant, $\quad{ }^{*} p<.05, \quad$ MR=ranked mentoring relationship: 1=low, 2=medium, 3=high 
groups (Table 3). To further estimate the capacity of natural mentoring relationship to ameliorate negative mental health, we ranked the impact of mentoring relationship scores as low (0-10), medium (11-20), and high (21-30) and examined the negative mental health performance of each rank for the 3 groups (Table 4).

\section{Results}

Demographic outcomes: 373 AIDS-orphaned (males=167, females=206), 285 other-causes orphaned (males=130, females=155) and 290 non-orphaned (males=113, females=177) children participated in the study. The majority (94\%) of the children are aged 10 to 17 years, a few (6\%) are aged 5 to 9 years; grand mean age $=13.59$ years $(S D=2.34)$. Orphans comprised $70 \%$ and non-orphans $30 \%$ of the children. Among the orphans ( $n=658$ ), $53 \%$ lost one parent (single orphans), $47 \%$ lost both parents (double orphans). There was no significant differences ( $F=.259(2), p=.77)$ of age in the 3 groups: Mean $=13.54(\mathrm{SD}=2.52), 13.55(\mathrm{SD}=2.11), 13.67(\mathrm{SD}=2.32)$, respectively, for AlDS-orphaned, other-causes orphaned, and non-orphaned children. Also no significant difference $(F=1.96(2), p=.14)$ of educational levels in the 3 groups was observed. There were significant more female than male participants in both the AIDS-orphaned $\left(X^{2}=4.08, p<.05\right)$ and non-orphaned $\left(X^{2}=14.12, p<.01\right)$ groups. However, significant gender difference on almost all variables of the mental health measures was not observed. These demographic outcomes suggest no undue interference of gender, age, or educational level on mental health outcomes in the 3 groups.

Psychosocial mental health: Children orphaned by AIDS showed significant $(p<.05)$ highest 
negative mental health factors in the 3 groups (Table 1), evidenced by highest child abuse, depression, social discrimination and anxiety scores in the group. Also AIDS-orphaned children showed significant $(p<.05)$ least positive mental health factors. Parental/foster care, social support, and self-esteem scores were significantly $(p<.05)$ lower in the AIDS-orphaned group than in the 2 control groups. Most (83\%) of the double orphans are AIDS-orphaned. Double orphans scored significant higher anxiety $(F=3.88, p<.05)$, lower self-esteem $(F=7.04, p<.01)$, lower social support $(F=6.03, p$ $<.05)$, and lower positive mental health factors $(F=6.04, p<.05)$ than did single orphans. However (Table 2), double orphans (whether AIDS or other-causes orphaned) showed similar levels of psychosocial mental health. No significant statistical difference was observed between both groups of orphans on all domains of the mental health measures. Among single orphans, who lost only one of their parents, however, significant mental health differences were found between AIDS and other-causes orphaned children.

Children who reported having a natural mentor $(n=714)$, showed significant lesser negative $(t=2.61$, $p<.01)$ and higher positive $(t=5.37, p<.01)$ mental health factors than did those who reportedly have no natural mentor ( $n=234)$. Significant lower child abuse $(p<.01)$, lower social discrimination $(p<.05)$, lower anxiety $(p<.05)$, higher social support, and higher self-esteem $(p<.01)$ were observed in the group than in children who reportedly have no natural mentor $(n=234)$. In the 3 groups (Table 3 ), AIDS-orphaned children, who have mentors, showed significant lower $(t=3.00, p<.05)$ negative mental health factors than did AIDS-orphaned children without mentors. In the control groups, although children having mentors showed lower negative mental health factors than those not-having, the variance was 
not significant. Furthermore, in the ranked perceived positive impact of the mentor's role on the psychological health of the children (Table 4), AIDS-orphaned children who scored high impact, showed significant $(p<.05)$ lower negative mental health factors than did those who scored medium and low impacts. Similar significant effects were not observed in the control groups. These outcomes suggest that the natural mentoring care may ameliorate negative mental health factors among AIDS-orphaned children, most of whom are without their two biological parents.

\section{Discussion}

The preponderance of interpersonal relation studies agree that social support is a potent factor for the psychological well-being of individuals (Uchino, Cacioppo, \& Kiecolt-Glaser, 1996). AIDS-orphaned children, in the present study, showed lowest scores on all domains of the social support measure. Friends and family members showed them the least love, least comforted them when they felt bad, least took care of their financial needs or helped them do things they could not do. Compared with children in the control groups, AIDS-orphaned children were, in general, significantly least satisfied with the social support from their environment. Two factors may precipitate low social support - social discrimination (Cluver et al., 2008) and parental loss (UNAIDS, UNICEF, \& USAID, 2004). Cluver et al. (2008) had reported highest levels of stigma/social discrimination among AIDS-orphaned than among non-AIDS and non-orphaned children. In the present study, however, we are less inclined for two reasons to point at social discrimination for the highest negative mental health factors observed in the AIDS-orphaned group. First, between all orphaned and non-orphaned children in the study, social discrimination experience was not significantly different. Second, in the 3 groups, although AIDS-orphaned children 
experienced higher social discrimination than did children in the control groups, their experience was not significantly different from that of non-orphaned children. Specifically, AIDS-orphaned children felt more differently treated, compared to other persons around them; felt more unfairly treated compared to others around; made to feel more inferior compared to others around; people behaved as though they were afraid of them more; and people tended to insult/abuse them more compared to others. But their encounters were only statistically difference from those of children orphaned by other causes. Against non-orphaned children, the social discrimination experience of the AIDS-orphaned children was similar -- suggesting no sharp case of purposeful discrimination against AIDS-orphaned children because of their orphan status. The capacity, therefore, of social discrimination to account for the negative mental health factors in the AIDS-orphaned children may be peripheral rather than substantive.

The majority of the AIDS-orphaned children are double orphans (having no biological parents); few double orphans are in the other-causes orphaned group. Needless to say there is no parental loss in the non-orphaned group. Double orphans $(n=319)$, irrespective of orphan status, scored significant higher anxiety, lower social support, lower self-esteem, and lower positive mental health factors than did single orphans ( $n=343$ ), whose one parent is living. Also double orphans, whether AIDS or other-causes orphaned, showed similar levels of negative and/or positive mental health factors. Child abuse, depression, social discrimination, anxiety, foster parental care, self-esteem, social support levels were similar between the two groups (Table 2), suggesting the shared effect of double orphanhood on mental health between children orphaned by AIDS and children orphaned by other causes. In the single orphans group, mental health variances were observed between the two orphan statuses (AIDS and 
other-causes orphaned children), suggesting the possible differential effects of being a maternal (mother deceased) or paternal (father deceased) orphan.

If double orphans are consistently (UNAIDS, UNICEF, \& USAID, 2004) more psychologically deprived than single orphans, and the majority of the AIDS-orphaned children in the present study are double orphans, then it seems plausible to adduce that double parental loss may account for the higher psychopathic mental health factors in the AIDS-orphaned children. What palliative care, therefore, may be required to ameliorate the effects of double parental loss and/or negative mental health factors in AIDS-orphaned children? We suggest the natural mentoring care.

In the present study, children who reported having a natural mentor $(n=714)$, showed better positive mental health factors than did those without mentors $(n=234)$. The effect of having a natural mentor on mental health seemed gender bias-free as no significant gender mental health difference was observed on all domains of the mental health tools. In the 3 groups (Table 3), the weight of having or not having a natural mentor on negative mental health factors was significant in the AIDS-orphaned group. Similar significant effect was not observed in the control groups. Furthermore (Table 4), in the AIDS-orphaned group, low mentoring relationship scores elicited significant higher negative and lower positive mental health factors than did medium and high mentoring relationship scores. Similar significant trend was not observed in the control groups, suggesting that the effect of natural mentoring relationship against negative mental health factors may be stronger among AIDS-orphaned children than among other groups.

The perceived palliative effect of natural mentoring relationship on negative mental health 
factors (Table 4) seemed likely among orphaned than among non-orphaned children. For example, in the two orphan groups, whereas high mentoring relationship scores elicited lower negative mental health factors than did medium and high mentoring relationship scores, the reverse was the case in the non-orphaned group. In the non-orphaned group, high mentoring provoked higher negative mental health factors than did medium and low mentoring. Although the reason for the converse negative mental health outcome is not clear, we are inclined to suspect parental interference. Non-orphans are more likely than orphans to live with biological parents who may be averse to the children's involvement in a mentoring relationship. To these parents, the mentor may be an unwelcome "intruder" in the family bond. Non-orphaned children, in this situation, may encounter social dissonance (conflict) that may distort the potentials of natural mentoring relationship.

\section{Limitations of the study}

First, the study is a cross-sectional experiment, not a longitudinal one. Thus the study outcomes are relational rather than causal. A study that may longitudinally examine mental health outcomes in AIDS-orphaned children before AIDS-defined parental illnesses, during AIDS-defined illnesses, and after parental death may be academically stimulating.

Second, we wished we were $100 \%$ certain of the cause of parental death in the AIDS-orphaned group. Death certificates are unreliable medical data (Cluver et al., 2008) in most AIDS-stigmatizing African countries. Cluver et al (2008) utilized the "verbal autopsy" method validated in several sub-Saharan African studies (Hosegood, Vanneste, \& Timaeus, 2004) to determine cause of parental 
death. The method required the presence of observable AIDS-defining illnesses such as oral candidiasis, Kaposi's sarcoma and the HIV wasting syndrome (WHO, 2005). In this study, $23 \%$ of the orphans self-reported AIDS as cause of father's death, and 35\% reported it as cause of mother's death. About half $(50.4 \%)$ stated "don't know" for father's death, and a lower rate $(40.6 \%)$ stated so for mother's death. However, "an especially important and distinctive characteristic of HIVIAIDS in regard to orphaning is that AIDS is more likely than other causes of death to create double orphans" (UNAIDS, UNICEF, \& USAID, 2004, p.11). We combined the UNAIDS criterion, orphans' self-report, and verbal autopsy from school and child support center heads to assign children to the AIDS-orphaned group.

Finally, $64 \%$ of the natural mentors are extended family members, only $36 \%$ are non-family members. Authors of organizational mentoring argue that a mentor should ideally be a non-family member. In natural mentoring, however, the participation of extended family members in child mentorship is culturally expedient (Rhodes et al., 1992). While we appreciate that some of these observations may strengthen the study outcomes, they do not, in our view, substantially negate them.

\section{Acknowledgements}

We are thankful to the Japan Society for the Promotion of Science (JSPS) for its generous financial grant for this study. We also thank the members and staff of the community school/NGO orphan and vulnerable children support centers in Mafikeng (South Africa) and Kampala (Uganda), where the study was conducted, for their cooperation for the study interviews. 


\section{References}

Abebe, T. \& Aase, A. (2007). Children, AIDS and the politics of orphans care in Ethiopia: The extended family revisited. Social Science \& Medicine, 64, 2058-2069.

Atwine, B., Cantor-Graae, E., \& Bajunirwe, F. (2005). Psychological distress among AIDS orphans in rural Uganda. Social Science \& Medicine, 61, 555-564.

Bagley, C. \& King, K. (1990). Child sexual abuse: The search for healing. London: Routledge.

Barrera, M., Jr. \& Prelow, H. (2000). Interventions to promote social support in children and adolescents. In D. Cicchetti, J. Rappaport, I. Sandler, R.P. Weissberg (eds), The promotion of wellness in children and adolescents. Washington DC, CWLA Press: 309-339.

Blascovich, J. \& Tomaka, J. (1991). Measures of self-esteem. In J.P. Robinson, P.R. Shaver, \& L.S. Wrightsman (Eds.). Measures of personality and social psychological attitudes, Volume I. San Diego, CA: Academic Press.

Chitiyo, M., Changara, D.M., \& Chitiyo, G. (2007). Providing psychosocial support to special needs children: A case of orphans and vulnerable children in Zimbabwe. International Journal of Educational Development, 28, No. 4: 384-392.

Cluver, L.D., Gardner, F., \& Operario, D. (2008). Effects of stigma on the mental health of adolescents orphaned by AIDS. Journal of Adolescent Health, 42 (4): 410-417.

Deininger, K., Garcia, M., \& Subbarao, K. (2003). AIDS-induced orphanhood as a systemic shock: 
magnitude, impact, and program interventions in Africa. World Development, Vol. 321, No. 7, pp.

1201-1220.

Detroit Area Study (1995) Measure of Discrimination. Available at <http://www.macses.ucsf.edu/Research/Psychosocial/notebook/detroit.html>.

DuBois, D.L. \& Silverthorn, N. (2005). Natural mentoring relationships and adolescent health: Evidence from a national study. American Journal of Public Health, Vol. 95(3): 518-524.

Furukawa, T., Yokouchi, T., Hirai, T., Kitamura, T., \& Takahashi, K. (1999). Parental loss in childhood and social support in adulthood among psychiatric patients. Journal of Psychiatric Research, 33, 165-169.

Faulstich, M.E., Carey, M.P., Ruggiero, L., Enyart, P., \& Gresham, F. (1986). Assessment of depression in childhood and adolescence: An evaluation of the Center for Epidemiological Studies Depression Scale for Children (CES-DC). American Journal of Psychiatry 143(8): 1024-1027.

Flaherty, J.A. \& Richman, J.A. (1986). Effects of childhood relationships on the adult's capacity to form social supports. American Journal of Psychiatry, 143: 851-855.

Gillespie, S., Norman, A., \& Finley, B. (2005). Child vulnerability and HIVIAIDS in sub-Saharan Africa: What We Know and What Can Be Done. Available at <http://www.ifpri.org/Themes/HIV/pdf/gillespieOVCsynth.pdf>

Goldberg, D.P. \& Hillier, V.F. (1979). A scaled version of the General Health Questionnaire. Psychological Medicine, 9, 139-145.

Hosegood, V., Vanneste, A., \& Timaeus, I. (2004). Levels and causes of adult mortality in rural South 
Africa: the impact of AIDS. AIDS, 5 (18), 663-71.

Lorenzo-Hernandez, J. \& Ouellette, S.C. (1998). Ethnic identity, self-esteem, and values in Dominicans,

Puerto Ricans, and African Americans. Journal of Applied Social Psychology, 28, 2007-2024.

Maxwell, E. (1998). "I can do it myself!" Reflections on early self-efficacy. Roeper Review, 20(3), 183-187.

MENTOR (2002). National Mentoring Partnership. Mentoring in America. Alexandria, Va. Available at http://mentoring.web.aol.com/common/one_report/national_poll_report_final.pdf.

Mbozi, P.S., Debit, M.B., \& Munyati, S. (Eds), 2006. Psychosocial conditions of orphans and vulnerable children in two Zimbabwean Districts. HSRC Press, Cape Town, South Africa.

Neale, M.C., Walters, E., Heath, A.C., Kessler, R.C., Perusse, D., Eaves, L.J., \& Kendler, K.S. (1994). Depression and parental bonding: cause, consequence, or genetic covariance? Genetic Epidemiology, 11: 503-522.

Nyblade, L., Pande, R., Mathur, S., MacQuarrie, K., Kidd, R., \& Banteyerga, H. (2003). Disentangling HIV and AIDS stigma in Ethiopia, Tanzania and Zambia. Available at <http://www.icrw.org/docs/stigmareport093003.pdf>.

Parker, G., Tupling, H., \& Brown, L.B. (1979). A parental bonding instrument. British Journal of Medical Psychology, 52, 1-10.

Paris, J., Zweig-Frank, H., \& Guzder, J. (1994). Risk factors for borderline personality in male outpatients. Journal of Nervous and Mental Disease, 182, 375-380. 
Pridmore, P. \& Yates, C. (2005). Combating AIDS in South Africa and Mozambique: the role of open, distance, and flexible learning (ODFL). Comparative Education Review, 49(4), 490-511.

Ragins, B.R. \& Cotton, J.L. (1999). Mentor functions and outcomes: a comparison of men and women in formal and informal mentoring relationships. Journal of Applied Psychology, Vol. 84, No.4, 529-550.

Ragins, B.R. \& McFarlin, D. (1990). Perception of mentor roles in cross-gender mentoring relationships. Journal of Vocational Behavior, 37, 321-339.

Rhodes, J.E., Ebert, L., \& Fischer, K. (1992). Natural mentors: an overlooked resource in the social networks of young, African American mothers. American Journal of Community Psychology, Vol. 20(4), 445-460.

Rosenberg, M. (1965). Society and the Adolescent Self-Image. Princeton, NJ: Princeton University Press.

Schwarzer, R. \& Schulz, U. (2000). Berlins Social Support Scales. Available at <http://userpage.fu-berlin.de/ health/soc_e.htm>

Scroufe, L.A, Carlson, E.A., Levy, A.K., \& Egeland, B. (1999). Implications of attachment theory for developmental psychopathology. Development and Psychopathology, 11, 1-13.

Sipe, C.L. (2002). Mentoring programs for adolescents: A research summary. Journal of Adolescent Health, 31, 251-260.

Subbarao, K., Mattimore, A., \& Plangemann, K. (2001). Social protection of Africa's orphans and other vulnerable children: issues and good practice program options. AFR HD working paper. 
Turnbull, A.P. \& Turnbull, H.R. (2001). Families, Professionals, and Exceptionality: Collaborating for Empowerment. Marrill, Prentice-Hall, Columbus, Upper Saddle River, New Jersey.

Tweed, J.L., Schoenbach, V.J., George, L.K., \& Blazer, D.G. (1989). The effects of childhood parental death and divorce on six-month history of anxiety disorders. British Journal of Psychiatry, 154, 823-828.

Uchino, B.N., Cacioppo, J.T., \& Kiecolt-Glaser, J.K. (1996). The relationship between social support and physiological processes: a review with emphasis on underlying mechanisms and implications for health. Psychological Bulletin, Vol. 119(3), 488-531.

UNAIDS, UNICEF, \& USAID (2004). Children on the Brink 2004. A Joint Report on New Orphan Estimates and a Framework forAction. UNAIDS, UNICEF, \& USAID, 1-42.

UNICEF (2003). Africa's orphaned generations. New York: UNICEF.

UNICEF (2004). The framework for the protection, care and support of orphans and vulnerable children: living in a world with HIV and AIDS. Available at <http://synkronweb.aidsalliance.org/OVC/documents/0000202e.pdf>.

Weissman, N.M., Orvaschel, H., \& Padian, N. (1980). Children's symptom and social functioning self-report scales: comparison of mothers' and children's reports. Journal of Nervous Mental Disorder, 168(12), 736-40.

World Health Organization (2005). WHO/Euro Report of the Technical Consultation on Clinical Staging of HIVIAIDS and HIVIAIDS Case Definitions for Surveillance. Copenhagen: WHO, 2005.

Zimmerman, M.A., Bingenheimer, J.B., \& Notaro, P.C. (2002). Natural mentors and adolescent 
resiliency: A study with urban youth. American Journal of Community Psychology, 30, 221-243. 